\title{
AN EXPERIMENTAL STUDY ON HEAT TRANSFER AND PRESSURE DROP OF AIR-SOLIDS TURBULENT FLOW INSIDE A HORIZONTAL TUBE WITH DIFFERENT ENTRANCE ANGLES
}

\section{M.S. ZAHRAN, S.A. ABDEL-MONEIM \& N.S. BERBISH. 1}

$$
\text { دراسة تجريبية لانتقال الحرارة واتخلاض الفنط لسريان سعل مضطرب داخل انبوب المتى . }
$$

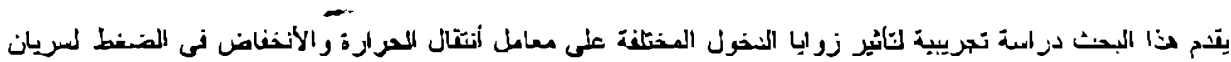

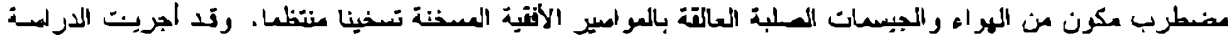

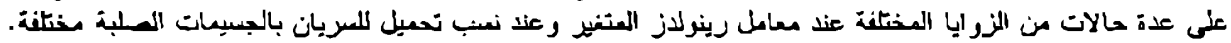

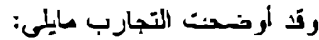

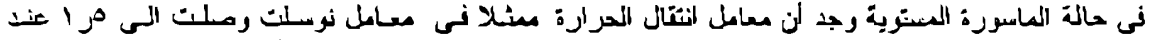

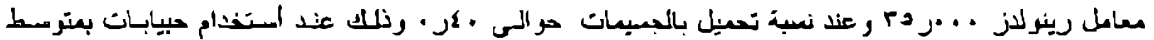

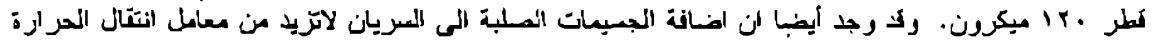

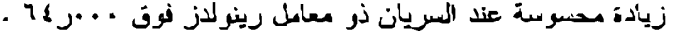

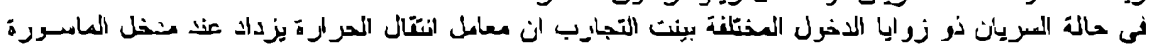

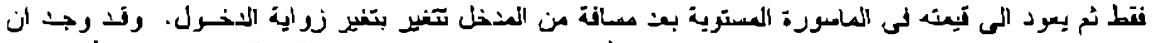

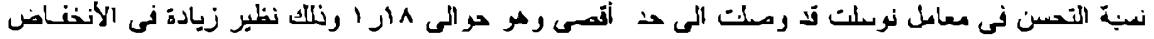

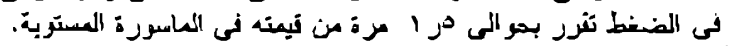

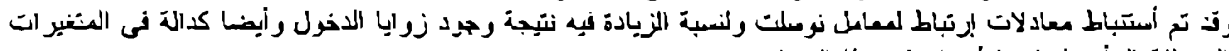

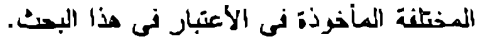

\begin{abstract}
The present work deals with the effect of turbulent air-sand suspension flow on heal transfer and pressure drop in horizontal tube with a uniform heat flux at different entrance angles. Four different inlet bend angles in addition to the case of plain tube $\left(\theta=0^{\circ}\right)$ were studied at different Reynolds numbers, sand particles of different average-sizes and different mass loading ratios.

It was obtained for the plain tube flow that the presence of the solid particles in turbulent flow enhances the heat transfer coefficient giving an enhancement ratio of the Nusselt number of $1.5 \mathrm{at}$ $M=0.4$ and $R e=35,000$ for panticles of 120 microns. Moreover, at higher Revnolds numbers (over $64,000)$ slightly enhancement in the heat transfer coefficient was observed. For the flow with different entrance angles, the heat transfer coefficient enhances in the upstream portion of the test-section. The results of clean-air flow show that about 1.18 fold increase in average Nusselt number was corresponding to about 1.5 fold increase in the pressure drop along the test-section. The presence of the solid particles in the flowing air enhances the heat transfer coeficient up to mass-loading ratio of $M=0.15$ and further addition of solids affects slightly the heat transfer coefficient.
\end{abstract}

New correlations for the Nusselt number and its enlancement ratio ivere oblained for both cases of plain tube and for the tube with different entrance angles.

\section{INTRODUCTION}

Turbulen! flow in $\mathrm{T}$-junction branchment is an important type that exists in a wide variety of engineering situations ranging from internal combustion engines manifolds and ventilation ducting to fluid devices.

\footnotetext{
${ }^{\prime}$ Mech. Engg. Dept., Shoubra Faculty of Engg, Zagazig University.
} 
In heat transfer and fluid flow applications, the existence of highly efficient thernal systems presents an important aim of most designers and researchers. This will bring about some savings in volumes and reduces overall weights [1]. In practice, several methods and techniques have been utilized to achieve this goal. Among these techniques is the inclusion of secondary and gas-solids flows. In these types of flows, abnormal turbulence are created. This in turn increases both the heat transfer rate and the pressure drop.

Davies and $\mathrm{Al}$-Arabi [2] carried out an experimental work to study the effect of inlet abnormal conditions on heat transfer under uniform heat flux with water as a working fluid. The tested inlet conditions are: $90^{\circ}$ angle bend, sharp edge and different orifices. They concluded that for values of $x / D$ (axial distance/diameter ratio) less than the critical value (thermal entrance length), the local heat transfer varies from one crosssection to another according to the amount of the abnormal turbulence. But, for values of $x / D$ greater than the critical, the local heat transfer is independent of $x / D$. Moreover, the critical values of $\times / D$ for the abnormal turbulence are higher than that for normal turbulence.

Khalil [3] carried out an experimental study for the effect of different orifices inserted at the tube inlet on heat transfer and pressure drop. Air as a working fluid, was flowing through a brass tube of $38 \mathrm{~mm}$ inner diameter and $4 \mathrm{~m}$ long under uniform heat tux conditions. Four different orifices were used. It was concluded that the thermal entry increases with the rising of either Reynolds number or turbulence intensities. However, for the same turbulence intensity the increase in the heat transfer coefficient is small compared with that in the pressure drop. Furthermore, after certain turbulence level no pronounced increase in heat transfer exists, while the pressure drop is still increasing

Moustafa [4] studied analytically the flow characteristics in a two-dimensional multidirection T-junction domain. The flow was treated as steady, incompressible and turbulent.

Abdel-Moneim [5] carried out an experimental study on the heat transfer and pressure drop characteristics of turbulent gas-solids flow in a horizontal tube of $40 \mathrm{~mm}$ inner diameter and $3 \mathrm{~m}$ long under constant heat flux. Two particle-sizes of 200 and 30 microns were suspended into a stream of air flow. It was concluded that the presence of the solid particles in the air flow increases the heat transfer coefficient and pressure drop. This increase depends strongly on both the Reynolds number and the solidsloading ratio. But, at higher range of $\operatorname{Re}($ over 60,000$)$ no significant increase in the heat transfer coefficient was observed. Also, no significant increase was obtained in the pressure drop with the addition of 30 microns particles, while the addition of 200 microns particles increases the pressure drop.

The present work is divided into two parts. The first part deals with the case where fully developed turbulent flow already exists at the commencement of heating. This condition is obtained for the plain tube flow when a calming section of sufficient length is used. The second part deals with the case where abnormal turbulent flow exists at the commencement of heating, due to the presence of a bend with different angles at the entrance to the test-section. 


\section{EXPERIMENTAL APPARATUS AND PROCEDURE}

The experimental set-up shown in Fig. (1) was used to study the effect of solids loadingratio and the entrance angle on the heat transfer characteristics. The test rig used in the present work comprises: an air passage, a solid particles feeding system, a different entrance angles, a heated test section with main and guard heaters, a solid panicles separation system (cyclones), and different measuring instruments. The test tube and the entrance angles were made of brass tubes with $40 \mathrm{~mm}$ inner diameter. The length of the test section tube was $3 \mathrm{~m}$ representing a length to diameter ratio of about 75 . Details of the entrance angles are shown in Fig.(2). The solids loading ratio based on the mass loading ratio was calculated from,

$$
M=\frac{\dot{m}_{p}}{\dot{m}_{f}}
$$

Where $\dot{m}_{p}$ and $\dot{m}_{f}$ are the solids and fluid (air) mass flow rates respectively.

The wall temperatures were measured along the test-section length at several test stations (40 different test positions) using thermocouples made of copper-constantan wires of $0.5 \mathrm{~mm}$ diameter of an accuracy of $\pm 0.5 \%$. Generally, two diametrically opposed, top-bottom, thermocouples were fixed on the test tube wall. While the pressure is measured at different locations along the tube by using a system of manometers at different locations along the tube.

The local heat transfer coefficient from the tube inner wall surface to the fluid flow for each segment of the test tube was calculated from:

$$
h=q^{\prime \prime} /\left(T_{s}-T_{m}\right)
$$

Where, $q$ "is the input heat flux and $T_{S}$ and $T_{m}$ are the wall surface mean and flow mean temperatures for each segment. Also, the local Nusselt number and Reynolds number were obtained as;

$$
\mathrm{Nu}=\frac{\mathrm{hD}}{\mathrm{K}_{\mathrm{f}}}
$$

and

$$
\operatorname{Re}=4 \dot{m}_{\mathrm{f}} / \pi \mathrm{D}_{\mu}
$$

Where, $h$ convective heat transfer coefficient, $D$ inner diameter of the test section, $K_{f}$ thermal conductivity of the fluid and $\mu$ the fluid dynamic molecular viscosity.

The clean air properies are evaluated at the flow mean temperature.

\section{RESULTS AND DISCUSSION}

In the present experimental work, the effect of various parameters such as Reynolds number, solids loading ratio, solid particles size and flow entrance angle on both heat transfer and pressure drop were investigated. The heat transfer coefficient was obtained for both clean and air-solids flow for abnormal and normal entrance conditions. 


\subsection{Clean-Air Flow Results}

The local Nusselt numbers were calculated along the test tube utilizing the present experimental data at different Reynolds numbers $(\operatorname{Re}=23400$ and 52400$)$ and at different inlet angles $\left(\theta=90^{\circ}, 30^{\circ}\right.$ and $\left.0^{\circ}\right)$. It was plotted axially against the dimensionless axial location $x / D$ at different entrance angles. Samples of the results are shown in Fig.(3). The local Nusselt number takes a relatively high value at the tube inlet, and this value decreases with the axial distance until it reaches an asymptotic value at the end of the thermal entry length then it begins to increase at the tube exit region. The phenomenon of increasing the local Nusselt number at the tube exit region may be attributed to the effect of the axial conduction through the tube wall. Figure (3) shows that, the value of the local Nusselt number at the tube inlet as well as its asymptotic value are functions of the associated Reynolds number.

Also the local Nusselt number distributions for the different entrance angles, shuwn in Fig. (3), take the same trend as that for the plain tube (angle $\theta=0^{0}$ ). Moreover, the existence of the entrance angle in the flow field enhances the local Nusselt number in the upstream portion of the test tube. The generation of the abnormal turbulence increases the value of the local Nusselt number above that for the plain tube at the same Reynolds number. This behavior may be attributed to the flow separation and reattachment that occurred immediately downstream of the test section inlet. However. in the absence of the tangential velocity component, the resulting turbulence appears to die down very rapidly after reattachment [6]. Consequently, the thermal entry length is increased above the value of the plain tube with increasing the entrance angle. A comparison between the obtained results from the present measurement with these published by Davies[2], is shown in Fig.(4). This comparison was made for the conditions of Reynolds number $(\mathrm{Re}-10700)$ and an entrance for clean air with the axial location $\times / D$ shows a very good agreement.

The average Nusselt number given in Fig.(5) is enhanced with increasing the entrance angle at different Reynolds numbers. The maximum value of the average Nusselt number enhancement ratio is about 1.18 at angle $\theta=90^{\circ}$. This maximum value is corresponding to nearly 1.5 -times increase in the pressure drop. Furthermore, the present experimental data for clean-air flow for both purely axial (plain tube) flow and flow with different entrance angles were used to correlate the average Nusselt number enhancement ratio with the entrance angle " $\theta$ " as,

$$
\overline{\mathrm{Nu}}=\overline{\mathrm{Nu}}\left(1+0.12 \theta^{1.12}\right)
$$

where,

$$
\overline{\mathrm{Nu}}_{\mathrm{o}}^{-}=0.01916 \mathrm{Re}^{0.8}
$$

This correlation is valid in the range of the entrance angles $\theta$ from 0 to $\pi / 2$ and Reynolds number from 10,000 to 58,000 . The results show that the Eq.(5) gives good agreement with the present experimental results within $\pm 6.4 \%$ deviation.

The effect of the entrance angles on the dimensionless pressure distribution along the tube is shown in Fig. (6). The results indicate a higher value of pressure drop in the upstream portion of the tube. This drop increases by increasing the entrance angle at the same Reynolds number at different entrance angles as shown in Fig. (7) ivhich 
shows that, the pressure drop ratio $\left(\Delta p / \Delta p_{0}\right)$ is highly affected by the entrance angles due to the increase in the flow separation [4].

\subsection{Air-Solids Flow Results}

For purely axial (plain tube) flow, the presence of the solid particles in the air flow enhances the heat transfer coefficient for both particle sizes within the experimental range of Reynolds number. This may be attributed to the increasing of the turbulence intensity with particles addition. The enhancernent ratio $\left(N u_{\infty} / N u_{\infty}, 0\right)$ which is defined by the ratio of the asymptotic Nusselt number for air-solids flow to that for clean air flow is shown in Fig.(8-A) for 200 microns particle size and Fig.(8-B) for 120 microns size. It is clear from Fig. (8) that the enhancement ratio approaches a maximum value about 1.50 at $R=35,000$ and $M=0.40$ for the flow with fine paricles (120 microns size). According to the dimensional analysis which have been performed by [7], the present experimental data was correlated relating the asymptotic Nusselt number with $\operatorname{Re}$ from 35,000 to 80,000 , solids-loading ratio $0 \leq \mathrm{M} \leq 0.4$ and ratio of particle diameter to tube diameter ( $\mathrm{d} / \mathrm{D}$ from $3 \times 10^{-3}$ to $5 \times 10^{-3}$ ). The comparison between the present correlation and the previous correlations is shown in the following table and in Fig.(9), and the agreement is good.

\begin{tabular}{|c|l|c|}
\hline Workers & \multicolumn{1}{|c|}{ Correlation } & \% Deviation \\
\hline Present & $N u_{\infty}=0.02105 \mathrm{Re}_{e}^{0.8} \cdot \mathrm{Pr}^{0.4}(\mathrm{I}+\mathrm{M})^{0.48}(1+\mathrm{d} / \mathrm{D})^{-0.2}$ & $\ldots \ldots \ldots$ \\
{$[5]$} & $N u_{\infty}=0.0212 \mathrm{R}^{0.8} \cdot \mathrm{Pr}^{0.4}(1+\mathrm{M})^{0.45}(1+\mathrm{d} / \mathrm{D})^{-0.15}$ & $-1.8 \%$ \\
{$[7]$} & $N u_{\infty}=0.0202 \mathrm{Re}^{0.8} \cdot \mathrm{Pr}^{0.4}(1+\mathrm{M})^{0.48}(1+\mathrm{d} / \mathrm{D})^{0.42}$ & $-55 \%$ \\
{$[8]$} & $N u_{\infty}=0.14 \mathrm{R}_{\mathrm{e}}^{0.6} \cdot(1+\mathrm{M})^{0.45}$ & $-12.5 \%$ \\
\hline
\end{tabular}

For Air-solids flow with different entrance angles, the results of the local Nusselt number for the two particles-sizes are shown in Fig.(10). The present results show that (for the two particle sizes) the local Nusselt number increases with the increase in both entrance angles and the solids loading ratios up to a value of solids loading ratio of about 0.15 . Over this value of the loading ratio, no significant enhancement in the local Nusselt number was observed. Also, it is observed that a longer thermal inlet length was obtained with higher entrance angle and higher loading ratio due to the longer axial distance required for decaying the abnormal turbulence.

Furthermore, the effect of the panicle size on the local Nusselt number is shown in Figs.(11-12). The results show that a dominant effect of smaller size particles than the coarser ones on the Nusselt number. This can be attributed to the higher number density of the smaller size for the same loading ratio [9].

A new correlation for the ratio of the average Nusseit number for air-solids flow with different entrance angles to the average Nusselt number for air-solids flow in plaintubes $\left(\overline{\left(\mathrm{Nu}_{s}\right)_{\theta}} /(\overline{\mathrm{Nu}})_{\mathrm{p} . \mathrm{t}}\right)$ was obtained by using the present experimental data. The 
present data were correlated by using the least square method and the following correlation was obtained:

$$
\frac{\left(\overline{\mathrm{Nu}_{\mathrm{s}}}\right)_{\theta}}{\overline{\left(\mathrm{Nu}_{\mathrm{s}}\right)_{\text {p.t. }}}}=1+0.994 \theta^{1.14}
$$

where

$$
{\overline{\left(N u_{s}\right.}}_{\text {p.t. }}=0.022 \operatorname{Re}^{0.8} \operatorname{Pr}^{0.4}(1+M)^{0.45}\left(1+\frac{d}{D}\right)^{-0.15}
$$

The present comelation Eq.(7) is valid within the range of the entrance angle of $(0 \leq \theta \leq \pi / 2)$, Reynolds number of $(25000 \leq \mathrm{Re} \leq 52,000)$, mass loading ratio of $(0 \leq \mathrm{M} \leq 0.25)$ and $\mathrm{d} / \mathrm{D}$ from $3 \times 10^{-3}$ to $5 \times 10^{-3}$. Equation.(8) was obtained by AbdelMoneim, [5] and it is valid within the range of Reynolds number up to 80,000 and solids loading ratio up to 0.25

\section{CONCLUSIONS}

1. For the two particle sizes, the presence of the solid particles in the air flow enhances the heat transfer coefficient. Also, the presence of solids, increases the pressure drop along the test-section.

2. For the flow with different entrance angles, the local Nusselt number enhances at the upstream portion of the rube only with increasing the entrance angle.

3. For clean-air flow with different entrance angles, the maximum entancement ratio of the average Nusselt number $(\overline{\mathrm{Nu}} / \sqrt[\mathrm{Nu}]{\mathrm{O}})$ is about 1.18 corresponding to nearly two times of the pressure drop ratio.

4. For clean air flow with different entrance angles, the following correlation for the average Nusselt number is valid within for a range of Reynold's number from 10,000 to 58,000 and entrance angel up to right angel.

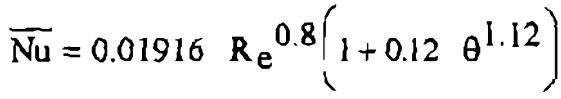

5 For air-solids flow at relatively low loading ratio (up to $M=0.15$ ) the local Nusselt number depends on both the entrance angle and solids loading ratio. Over this value of the loading ratio, no significant increase in the local Nusselt number was observed.

6. The asymptotic Nusselt number for purely axial (plain-tube) flow was correlated within the range of Reynolds number from 32,000 to 80,000 and solids loading ratio up to 0.4 as; $N_{u_{\infty}}=0.02105 R_{e^{0.8}} \cdot \operatorname{Pr}^{0.4}(1+M)^{0.48}(1+d / D)^{-0.2}$.

7. New correlation for the ratio $\left(\overline{\left(\mathrm{Nu}_{s}\right)_{\theta}} / \overline{\left(\mathrm{Nu}_{s}\right)_{\mathrm{p} . t .}}\right)$ was formulated as, $\frac{\left(\overline{N u_{s}}\right)_{\theta}}{\left(\overline{N u_{s}}\right)_{\text {p.t. }}}=1+0.0994 \theta^{1.14}$ 


\section{NOMENCLA TURE}

C Specific heat.

D Inner diamerer of the test-section,

d Solid particles mean size,

h Convective heat transfer coefficient,

K Therrnal conductivity,

L Total length of the test-section,

in Mass llow rate.

$q^{\prime \prime}$ Heat flux,

T Temperature,

$x$ Axial distance measured from tube inlet,

u Flow velocity

Greek letrers

$\Delta$ Difference

4 Dynamic molecular viscosity

$\theta$ Entrance angle

$\rho$ Density

Subscripts

$|\mathrm{J} / \mathrm{Kg} \mathrm{K}|$

[m]

(m)

$\left[\mathrm{W} / \mathrm{m}^{2} \cdot \mathrm{K}\right]$

[W/m.K]

(m)

[Ke/S

$\left[\mathrm{W} / \mathrm{m}^{2}\right]$

(K)

[m]

[m/s]

[N.S/m'

[rad]

$\left[\mathrm{Kg} / \mathrm{m}^{3}\right]$

Without solid particles (case of clean air flow)

f Fluid (gas) phase

p Particle phase

p.t. Plain-tube flow

S Flow with solids

$\infty$ Asymptotic value

$\theta$ Fow with entrance angle

Dimensionless Groups

M Solids-loading ratio.

$M_{C}$ Solids to gas thermal capacity ratio

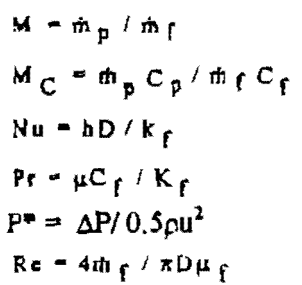

$\operatorname{Re}-4 \mathrm{~m}, \mathrm{KD} \mu_{\mathrm{f}}$

Nu Nusselt number.

Pr Prandd number

P* Dimensionjess pressure

Re Reynolds number

\section{REFERENCES:}

1. Mostafa G.M., "Effect of Swirling Angle and Swirls Number on Heat Transfer and Pressure Drop in Turbulemt Tube Flow". M. Sc. Thesis. Faculty of Engg.. Cairo University, 1987.

2. Davies, V.C. and Al-Arabi, M., "Heat Transfer Between Tubes and A Fluid Flowing Through Them With Varying Degrees of Turbulence Due To Entrance Conditions". Institution of Mech. Engg., West Minster, London, Vol. 169. No. 48, pp. 993-1006, 1965

3. Khalil, E.E., "Heat Transfer by Forced Convection in The Enrry Sections of Tubes"., M. Sc. Thesis, Faculty of Engg. Cairo University, 1973.

4. Mostafa A.A.A., "A Numerical Analysis of Turbulent Flow in Multi-directional T-Junction.". The First ICEMP., Cairo Egypt. Feb. 1991.

5. Abdel-Moneim S.A., "Heat Transfer to Air-Solids Turbulent Flow in Pipes", Ph.D. Thesis, Faculty of Engg., Cairo University, 1992.

6. Guo, $Z$ and Dhir, V.K., "Single-And Two-Phase Heat Transfer in Tangential Injection-Induced Swirl Flow". Int. J. Heat and Fluid Flow. Vol. 10. No. 3, pp. 203-210, Seplember 1989.

7. Abdel-Moneim. S.A., "Heat Transfer to Air in Turbulent Pipe Flow Widl Suspended Solid Powder.". M.Sc. Thesis, Faculty of Engg. Cairo University, 1989

8. Farber, L. and Morley, M.Y., "Keat Transfer in Flowing Gas-Solids Mixtures in A Circular Tube.", Ind \& Eng. Chem., Vol. 49, pp. 1143-1150, 1957.

9. Abou-Amb. T.W. and Abou-Ellail, M.M.M., "Modulation of Heat Transfer Dusty-Gas Pipe Flows.". Proc 6 Int. Conf. For Mechanical Power Engineering Hosted by Monoufia University., Cairo, 1986. 


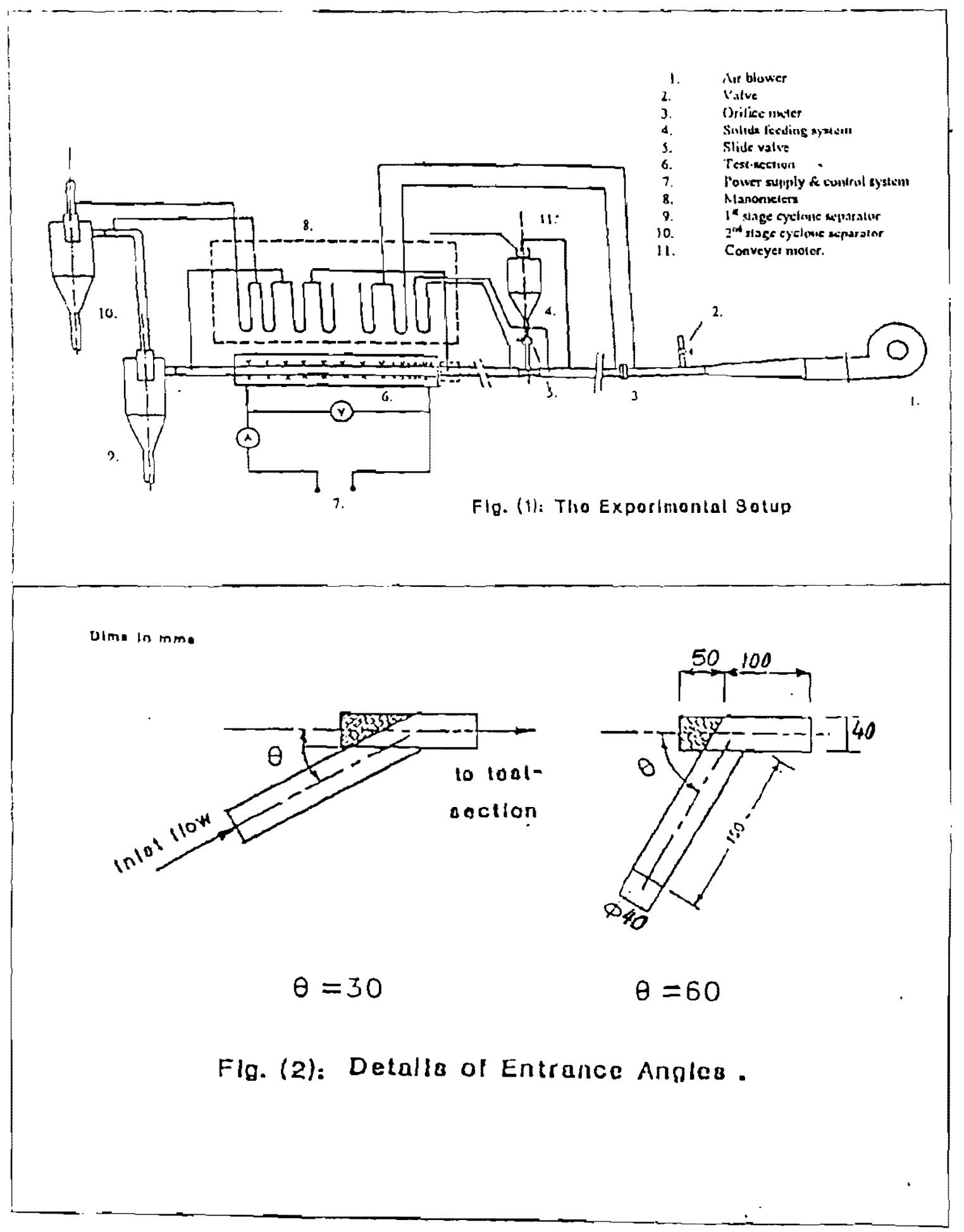



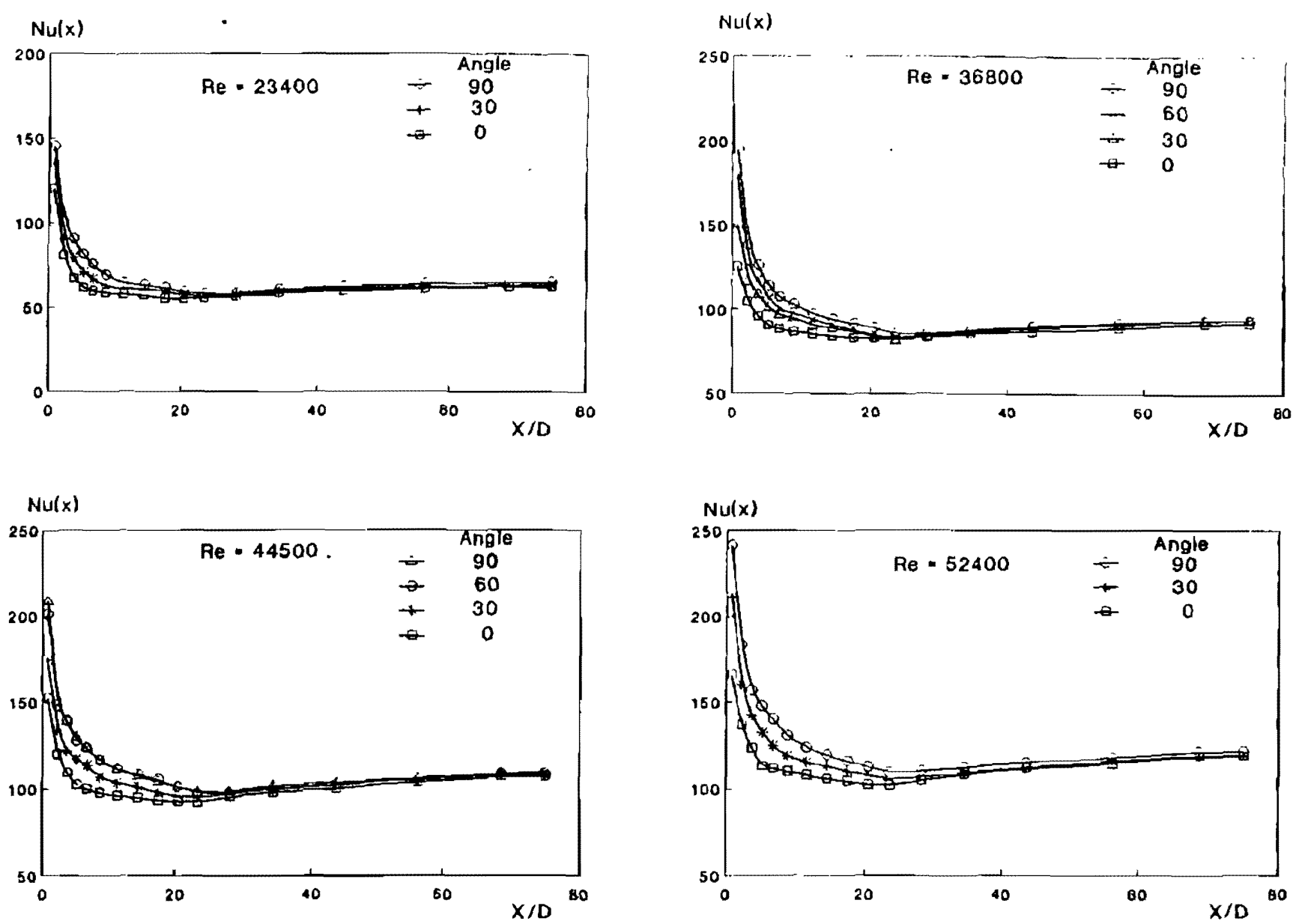

Fig.(3): Local Nusselt Number for Clean-Air Flow at Different Reynolds Numbers and at Different Entrance Angles. 


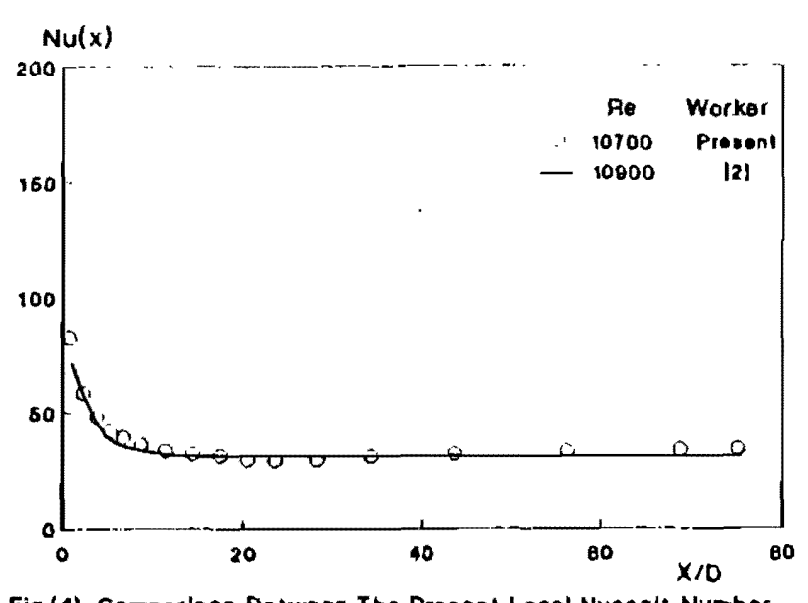

Fig.(4): Comperison Between The Prasent Local Nusselt Number for Clean-Air Flow and The Resulio of $\{2\}$ at en Angle 0.90
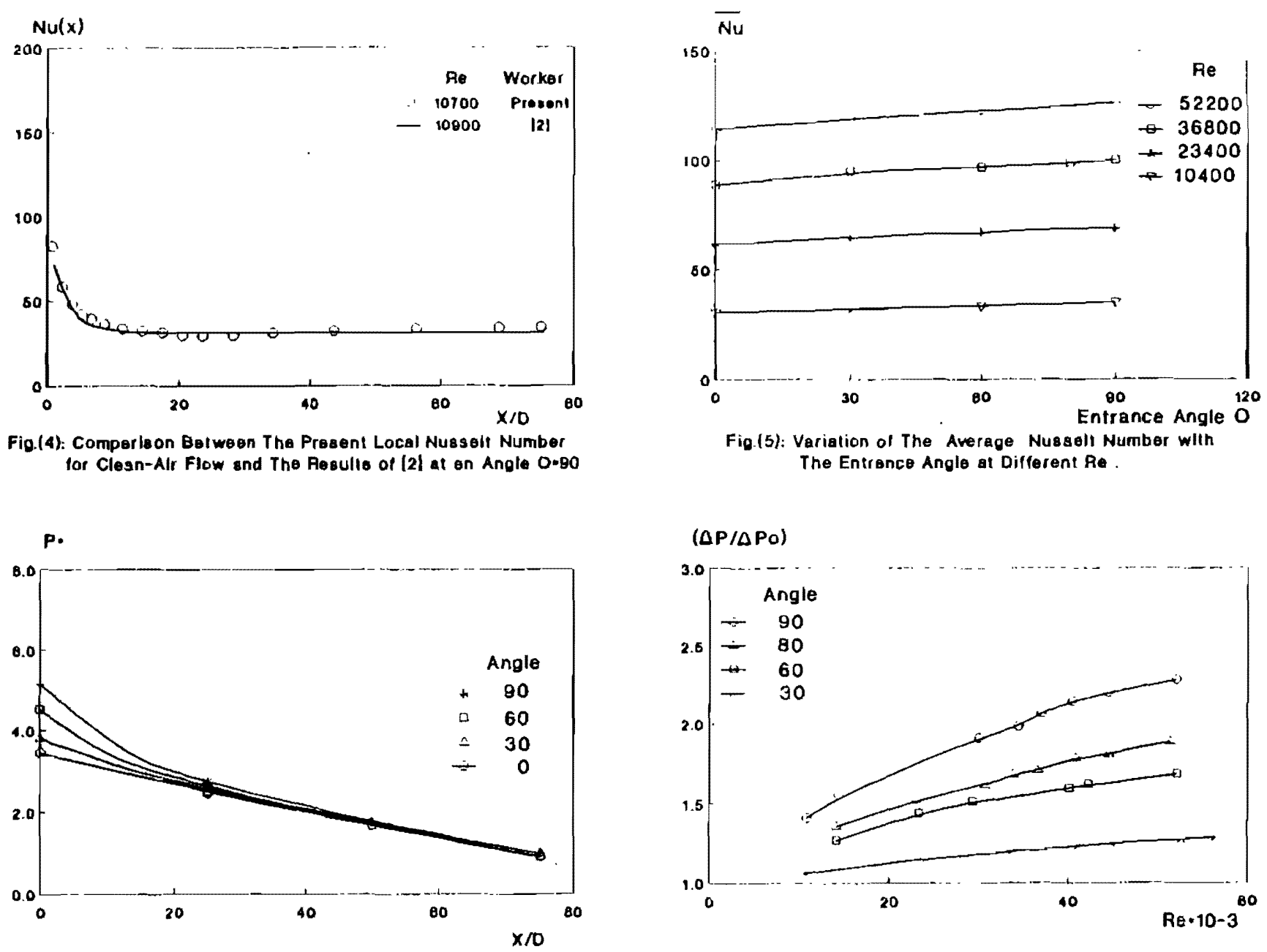

Fig.(6): Dimensionless Preseufe Distribution at Different Entrance Angles \& Pa -2400

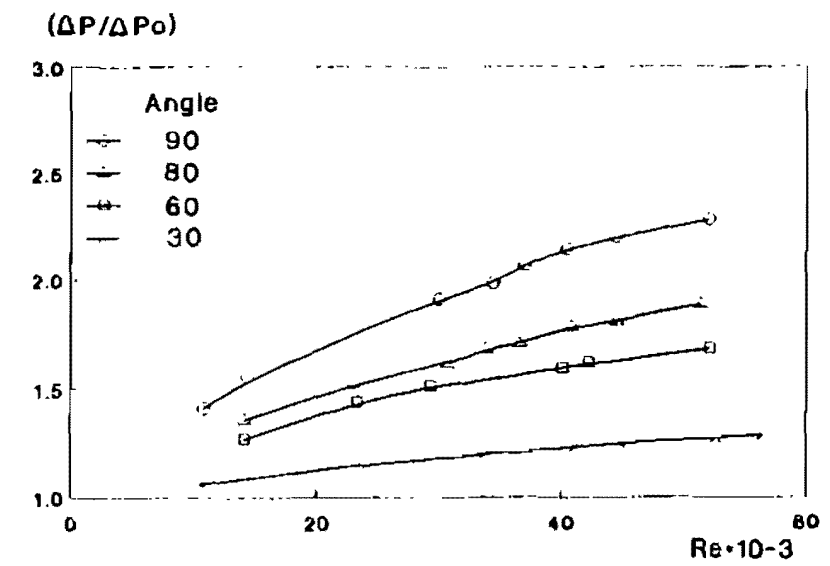

Fig.(7): Variation of The Pressure Drop Ratio with Reynolds Number at Different Entrance Angles. 
(Nu/Nu.o)

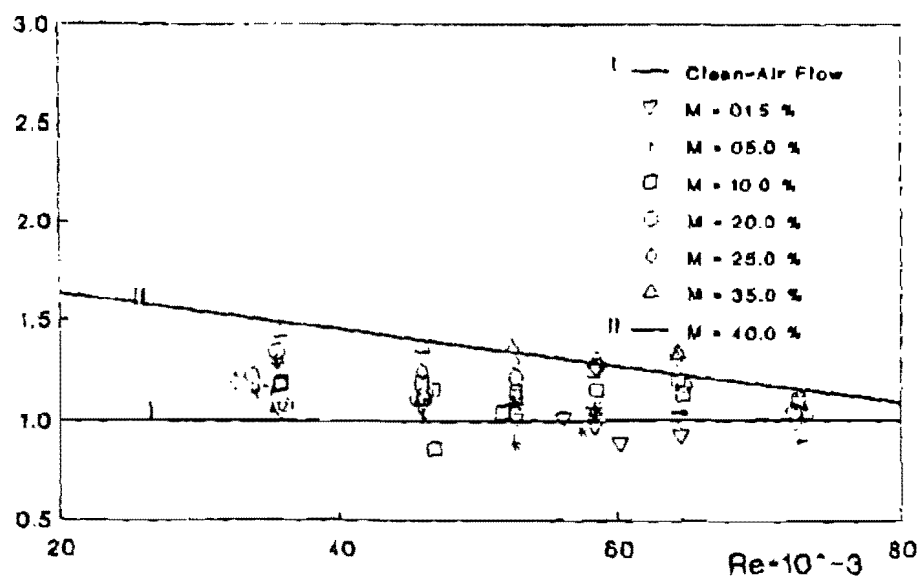

(A): Particles Average Size o* 200 um

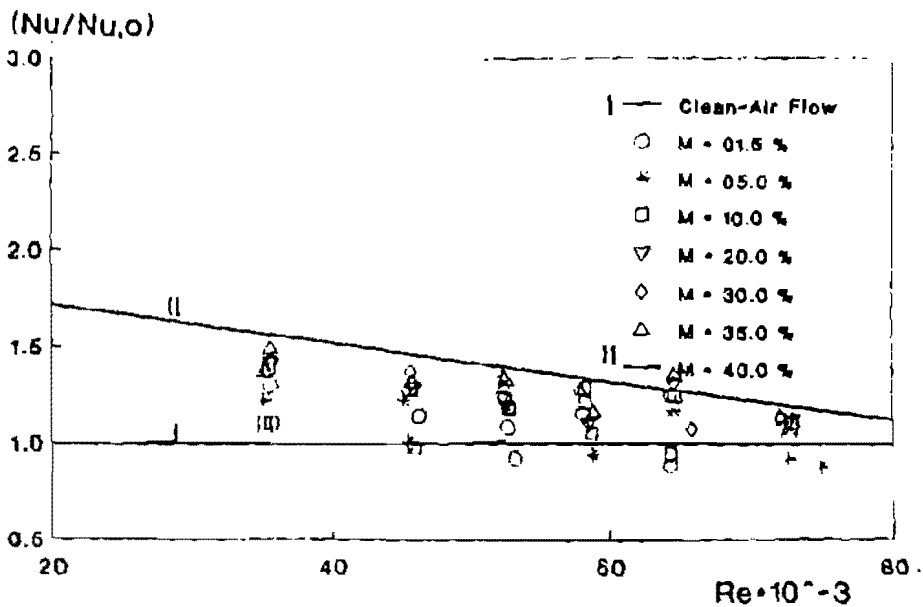

(B): Particles Average Size $d=120$ um

Fig.(8):Average Nussolt Number for Plain-Tubo

Air-Solids Flow at The Two Partlcle-sizes

Nu*

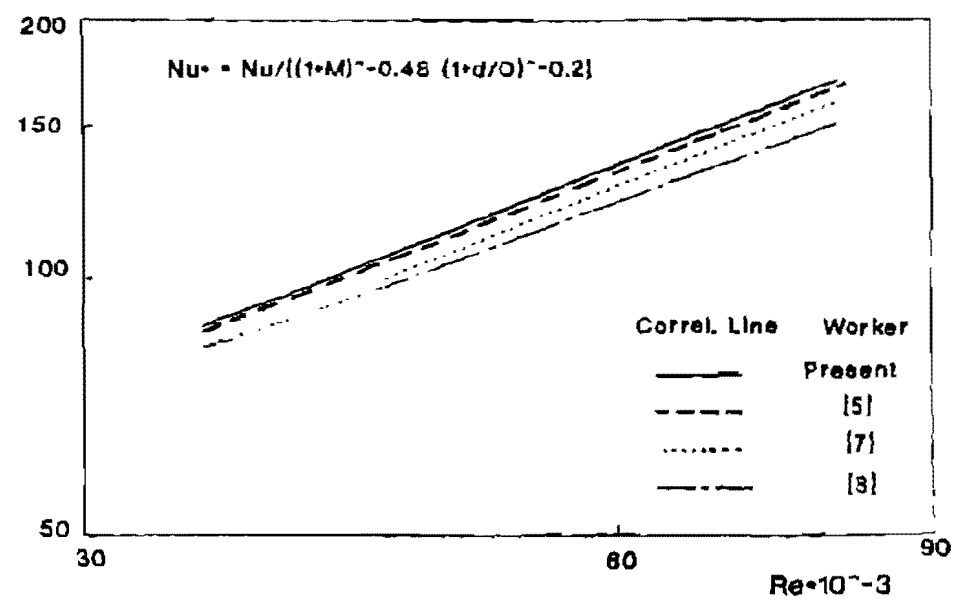

Fig.(9): Comparison Between the Present and Previous Correlations For Gas-Solids Flow \& Plain Tube. 

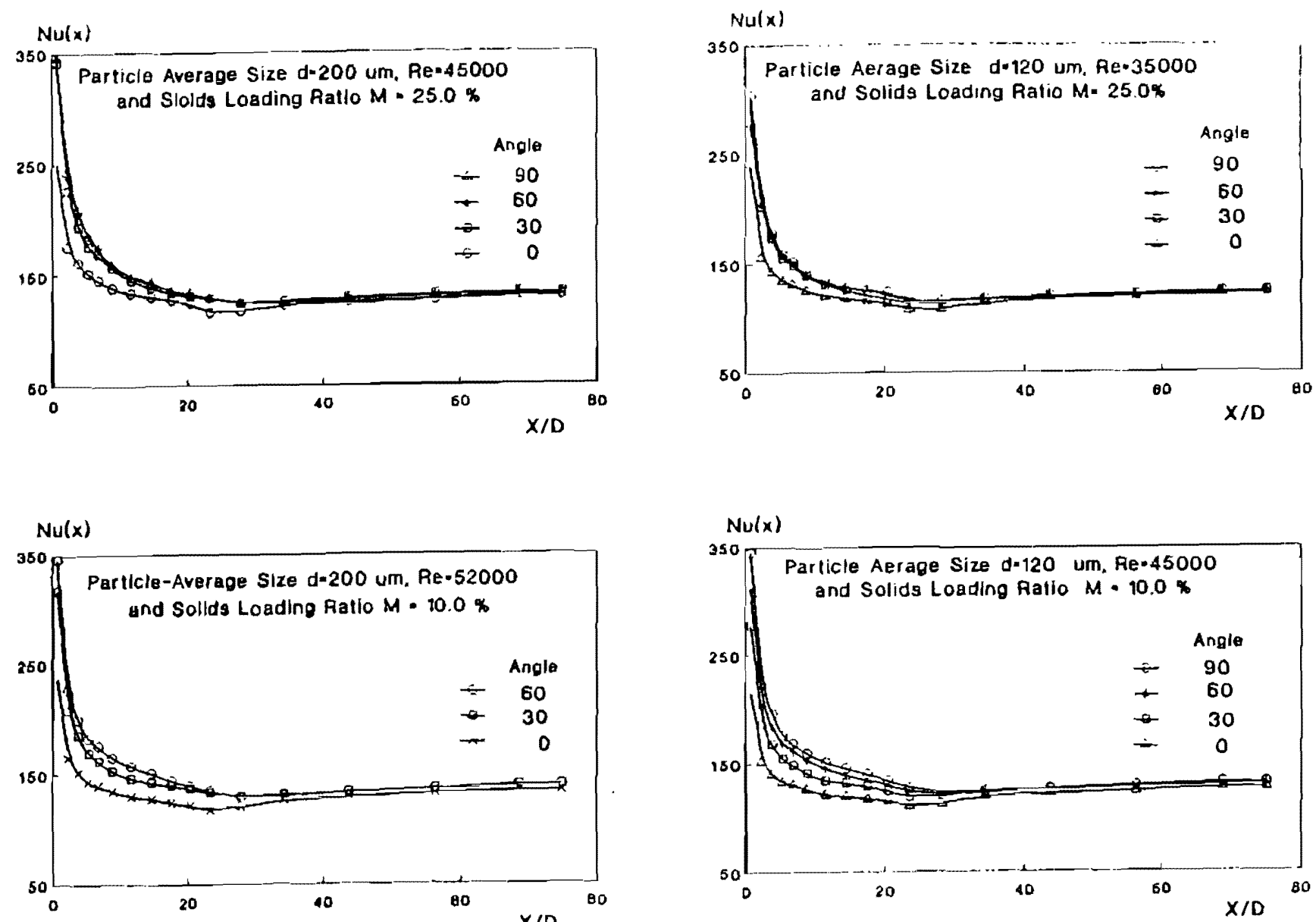

Fig.(10): Local Nusselt Number for Air-Solids Flow at Different Reynolds Numbers and at Different Entrance Angles. 


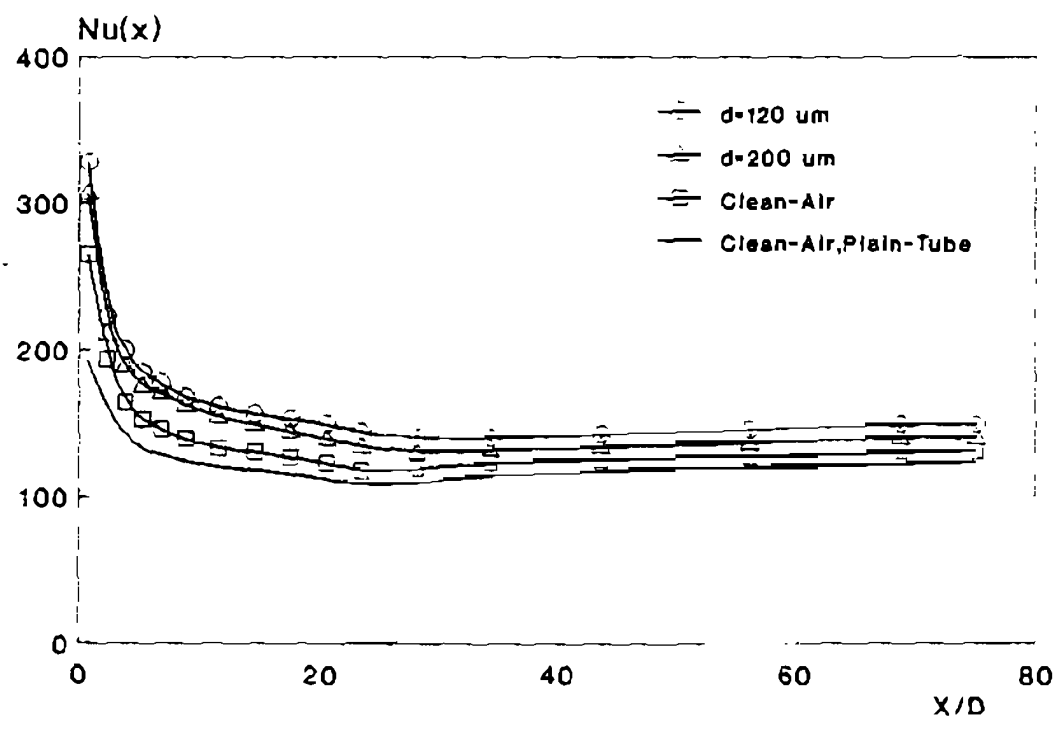

Fig.(11): Local Nussell Number for The Two Particle-Sizes at Re- 58200 for Angle $\theta-30 \& M=5.0 \%$.

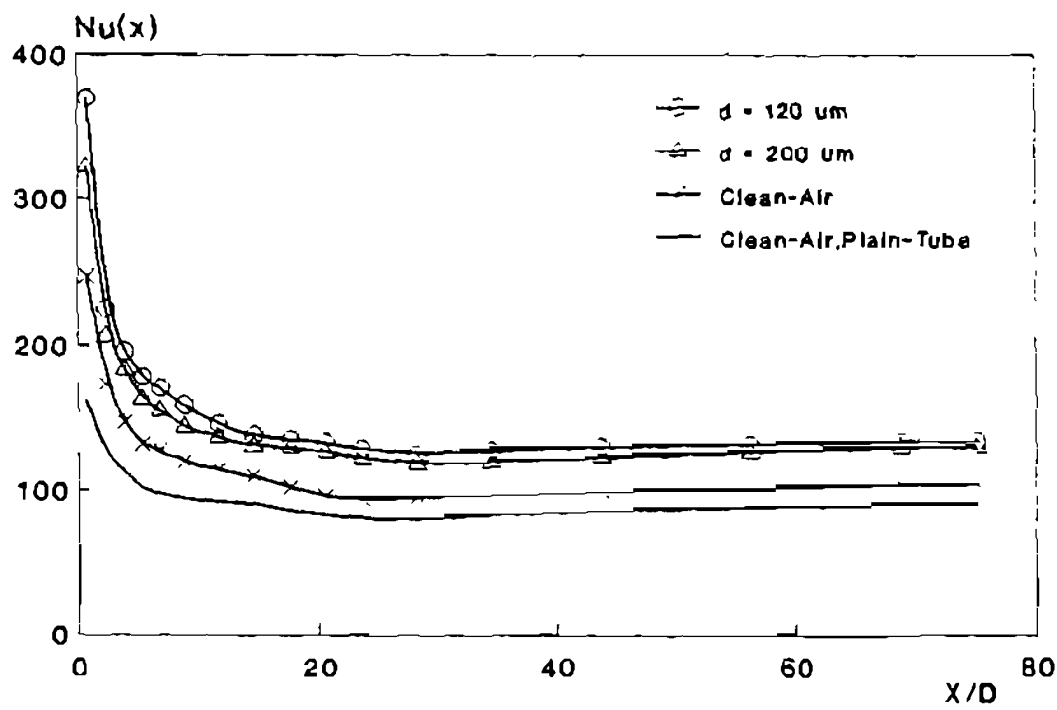

Fig.(12): Local Nusselt Number for The Two Particle-Sizes at Re $44500, \theta .608 M-15.0 \%$ 